\title{
Ultrastructural features of herpesvirus-infected cells in epidermal lesions in larvae of the Japanese flounder Paralichthys olivaceus
}

\author{
Teruo Miyazaki* \\ Faculty of Bioresources, Mie University, 1577 Kurima-machiyacho, Tsu, Mie 514-8507, Japan
}

\begin{abstract}
An electron microscopic study (EM) was performed on herpesvirus-infected cells in epidermal lesions of larvae of the Japanese flounder Paralichthys olivaceus to document the ultrastructure of the lesions. Epithelial cells were the primary cell type infected with the herpesvirus, and showed nuclei containing nucleocapsids, vesicles containing enveloped virions in the cytoplasm, and the release of enveloped virions through the cell membrane. Herpesvirus-infected cells were highly vacuolated and necrotic showing fragmented nuclei while these cells retained firm desmosomes to prevent separation from neighboring necrotic cells, which caused cellular aggregation in the upper layer of the epidermis. Based on EM results, the definitive pathological change was necrosis of epithelial cells infected with the flounder herpesvirus; therefore, the name Viral Epidermal Necrosis (VEdN) is appropriate for this herpesvirus infection.
\end{abstract}

KEY WORDS: Viral Epidermal Necrosis • Flounder herpesvirus · Japanese flounder larvae • Paralichthys olivaceus

Resale or republication not permitted without written consent of the publisher

\section{INTRODUCTION}

An unclassified herpesvirus has caused mass mortalities in the larval and juvenile stages of the Japanese flounder Paralichthys olivaceus since 1985, although mortality due to this herpesvirus has declined in recent years. This herpesvirus was demonstrated to be pathogenic to flounder only, and epithelial cells in the epidermis were revealed to be the primary cell type infected with the virus (Iida et al. 1989, Miyazaki et al. 1989). Diseased fish usually displayed patchy lesions of the thickened epidermis in the fins and body surface consisting of rounded cells. Therefore, the term Viral Epidermal Hyperplasia (VEH) was proposed to describe this disease condition based on the occurence of the thickened epidermis (Muroga 1997), whereas Viral Epidermal Necrosis (VEdN) was proposed based on the histological findings of the epidermal necrosis (Miyazaki et al. 1989). Hyperplasia and necrosis are very different pathological changes in cells. It is inappropriate that 1 disease has 2 different names, especially since those names indicate 2 different disease processes. This confusion appears to be caused by an insufficient description of the herpesvirus-infected cells at an ultrastructural level.

In the present study, electron microscopy (EM) was performed to reveal herpesvirus-infected cells in the epidermal lesions in flounder Paralichthys olivaceus and the ultrastructure was documented. Based on our observations, the name 'Viral Epidermal Necrosis' is proposed again for this herpesvirus infection.

\section{MATERIALS AND METHODS}

Ten larvae of Japanese flounder (approximately $40 \mathrm{~d}$ old) with patchy epidermal lesions which appeared under light microscope to be characterized by epi- 
dermal thickness and an increased number of round cells were fixed in $70 \%$ Karnovsky's solution and postfixed in $1 \% \mathrm{OsO}_{4}$. Small portions of the fins and skin with thickened lesions were processed for EM according to standard methods (Miyazaki et al. 1989).

\section{RESULTS}

An EM evaluation of the epidermal lesions revealed that all affected cells were epithelial and infected with a herpesvirus. These infected cells usually occurred in the upper layer of the epidermis while uninfected cells were present in the basal region. Infected cells displayed many different stages of damage associated with virus maturation. Some infected cells showed nuclei containing many nucleocapsids with a core (100 to $120 \mathrm{~nm}$ ) and empty capsids hexagonal in shape (Figs. $1 \& 2 \mathrm{C}$ ). The nuclei containing a small number of nucleocapsids had increased in size and had fine granular chromatin and fragmented nucleoli (Fig. 2C). The nuclei containing a large number of nucleocapsids had decreased in size and had coagulated chromatin and partially destroyed nuclear membranes (Fig. 1). Virions with a thick envelope (145 to $190 \mathrm{~nm}$ ) were found within vesicles in the cytoplasm. Vesicles containing 1 to several enveloped virions were present between the nuclei and the cell membrane (Figs. 1 \& $2 \mathrm{~A}, \mathrm{~B})$. These cells have cytoplasm consisting of a fine granular matrix containing many mitochondria with

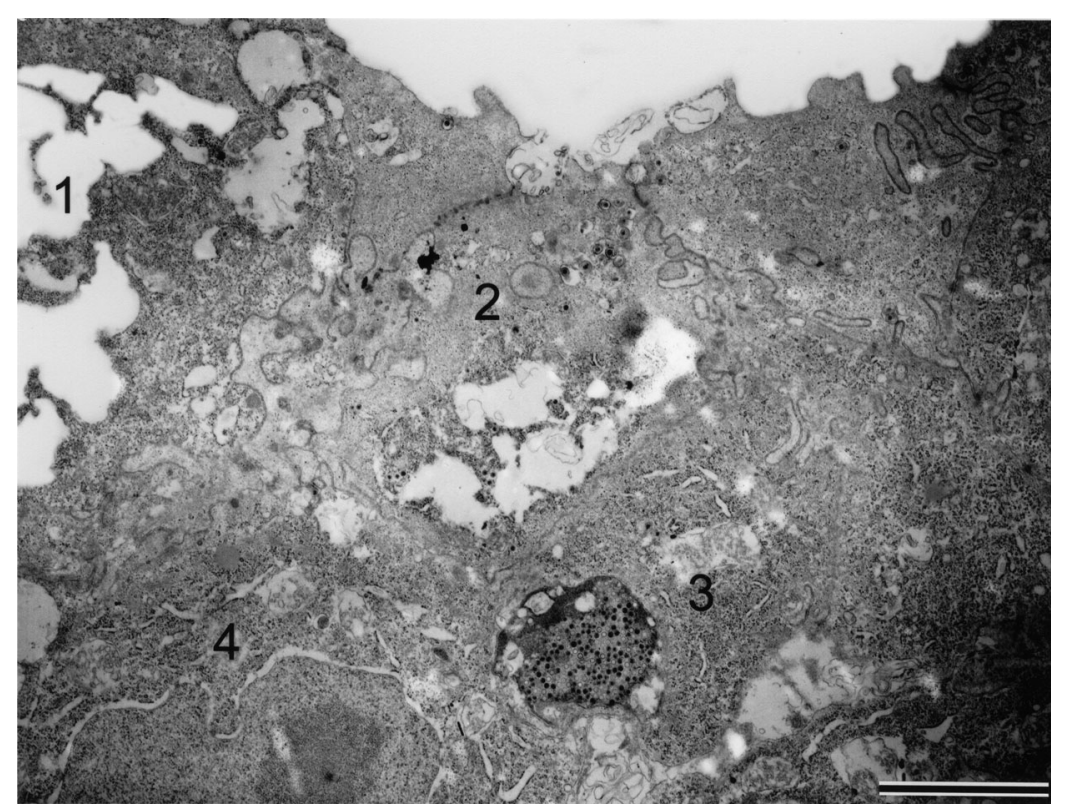

Fig. 1. Paralichthys olivaceus. Epithelial cells infected with a flounder herpesvirus. Cell 1 is markedly necrotic. Cell 2 shows a fragmented nucleus and vacuolization. Cell 3 shows a nucleus including many nucleocapsids. Cell 4 is an uninfected cell. Scale bar $=3000 \mathrm{~nm}$ slightly damaged membranes and cristae, normalappearing rER (rough-surfaced endoplasmic reticulum) and free ribosomes, slightly expanded sER (smooth-surfaced endoplasmic reticulum), and some vacuoles. In the outermost layer of the epidermis, infected cells released enveloped virions through the cell membrane where the cells formed protrusions (Fig. 2A,B). Some of virions were contained within a membrane while others were free. These cells maintained desmosomes between neighboring infected cells (Fig. 2A).

Infected cells in the advanced stage were highly vacuolated and had fragmented nuclei, although portions of the fragmented nuclei contained a small number of nucleocapsids (Figs. 1 \& 2C,D). The nuclear membranes were destroyed and, therefore, nucleocapsids were freely present in the cytoplasmic matrix, while some vesicles contained enveloped virions. These cells retained fine desmosomes to prevent them from separating from each other (Fig. 2C). Severely necrotic cells with a markedly fragmented nuclei were highly vacuolated and the cytoplasmic matrix was coagulated (Figs. 1 \& 3). Portions of fragmented nuclei contained coagulated chromatin and some nucleocapsids while the remaining vesicles contained enveloped virions as well as unenveloped viral particles (Fig. 3B). Surprisingly, these necrotic cells did not separate from neighboring necrotic cells (Fig. 3A). In the deeper region of the epidermis cells that were normal in appearance were present. These cells contained slightly enlarged nuclei with considerable euchromatin and apparent nucleoli (Fig. 1).

\section{DISCUSSION}

As previously stated, this flounder herpesvirus infection has 2 contradictory names: Viral Epidermal Hyperplasia (VEH), based on the thickened epidermis (Muroga 1997), and Viral Epidermal Necrosis (VEdN), based on histopathological signs (Miyazaki et al. 1989). In the present study, EM revealed that all degenerated and necrotic cells had been infected with the herpesvirus. These herpesvirusinfected cells were observed to be round-shaped under light microscopy of fresh materials. Because herpesvirus-infected cells retained undamaged desmosomes, these cells had barely separated from the neighboring cells even though these cells were 

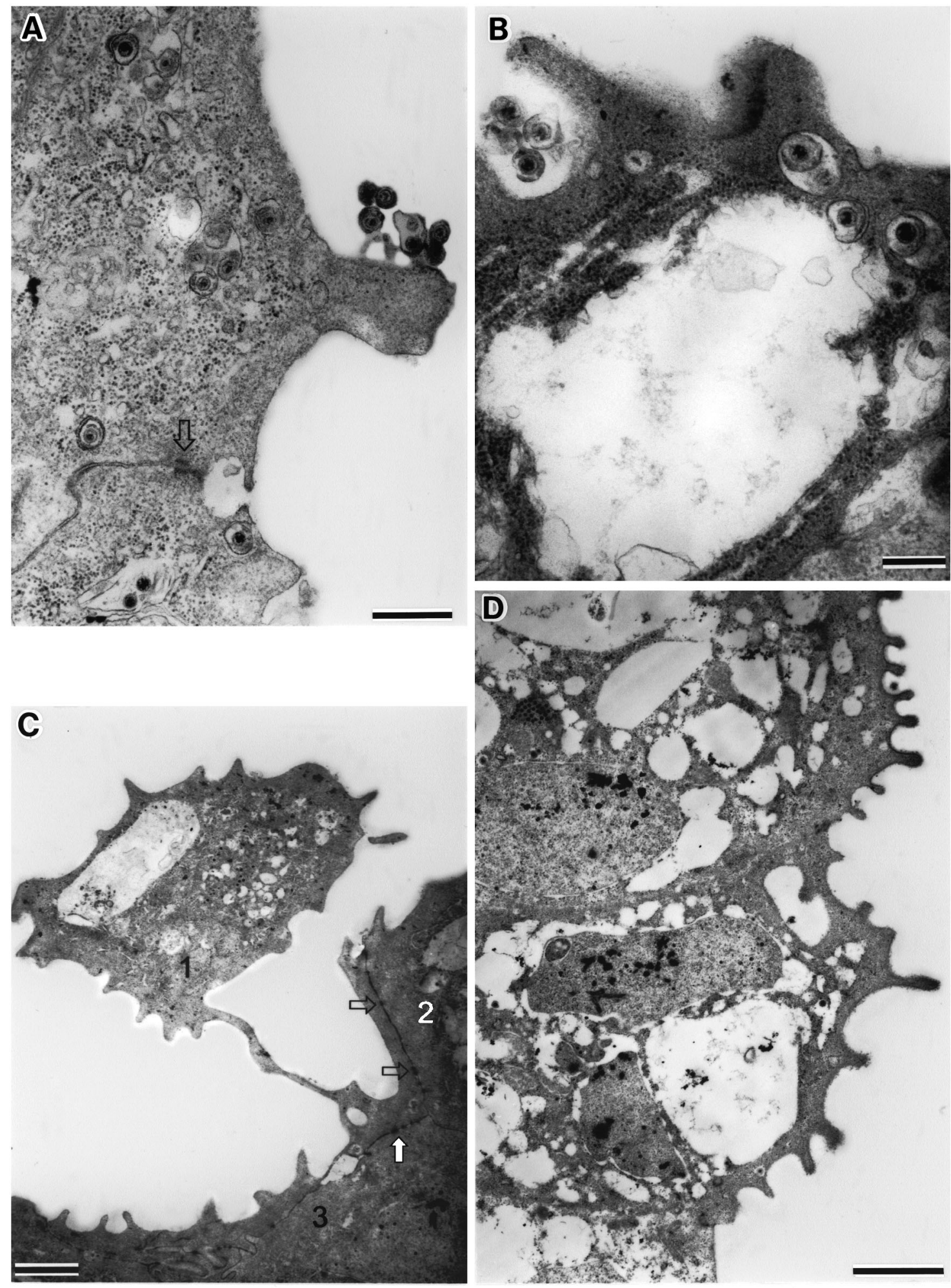

Fig. 2. Paralichthys olivaceus. Herpesvirus-infected cells in the uppermost layer of the epidermis. (A) The cells release enveloped virions, which are contained in a membrane. Notice a fine desmosome (arrow). Scale bar $=500 \mathrm{~nm}$. (B) Some enveloped virions are released through the cell membrane and others are contained in intracytoplasmic vesicles. Scale bar $=300 \mathrm{~nm}$. (C) Cell 1 is markedly necrotic showing a fragmented nucleus. Cell 2 is necrotic with vacuolization. Cell 3 shows a nucleus containing a small number of nucleocapsids. Notice fine desmosomes (arrows) between Cells 1 and 2, and Cells 1 and 3 . Scale bar $=2000 \mathrm{~nm}$. (D) The cells are necrotized and show vacuolization and fragmented nuclei. Scale bar $=4000 \mathrm{~nm}$ 

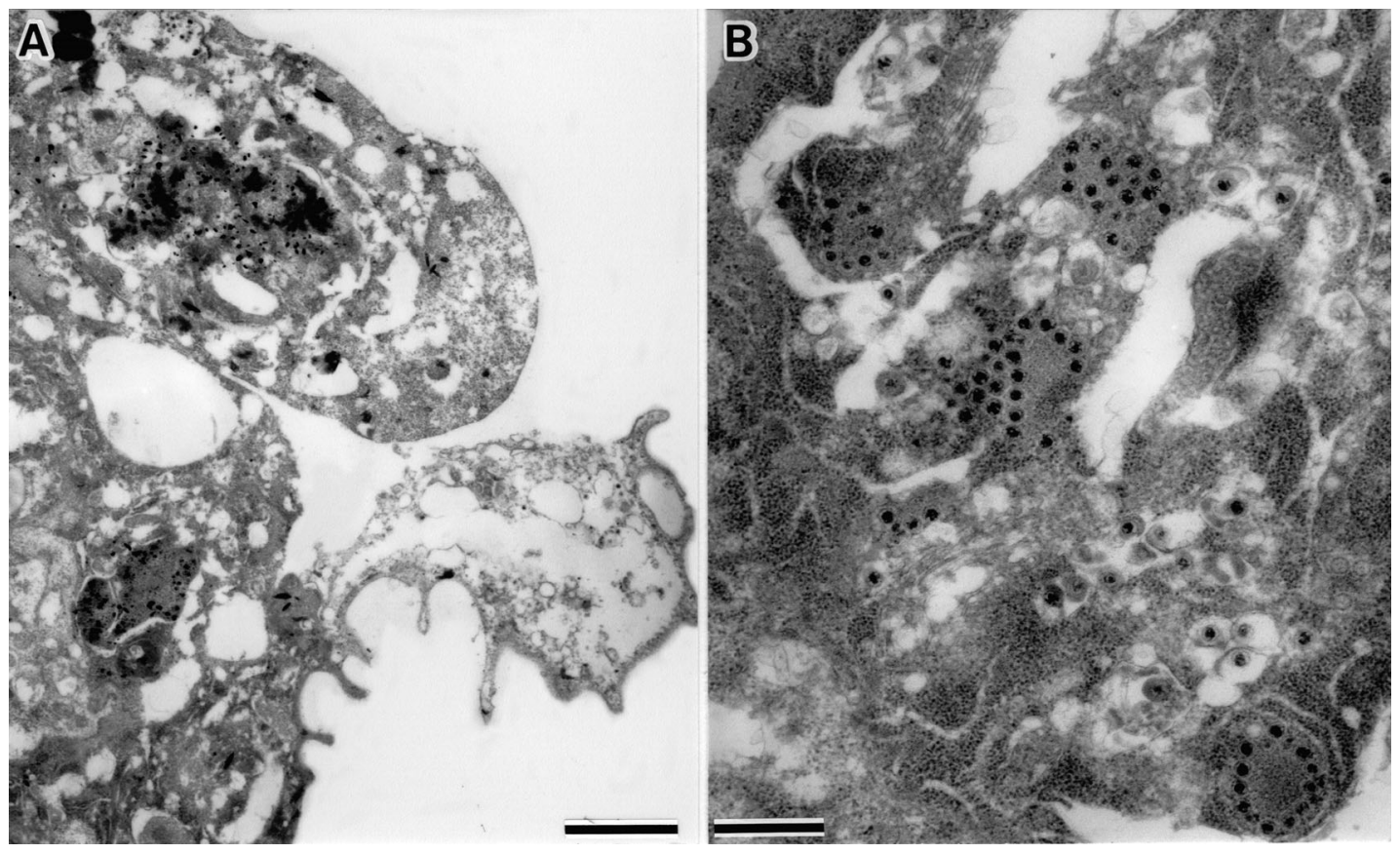

Fig. 3. Paralichthys olivaceus. (A) Herpesvirus-infected cells in the uppermost layer of the epidermis, which are markedly necrotic showing vacuolization and fragmented nuclei. These cells barely separate although they are severely necrotic. Scale bar $=2000 \mathrm{~nm}$. (B) Detail of a necrotic cell. Pieces of the fragmented nucleus contain coagulated chromatin and nucleocapsids while the remaining vesicles contain enveloped virions and unenveloped virus particles. The cytoplasmic matrix is coagulated. Scale bar $=600 \mathrm{~nm}$

markedly necrotic. Upon histological examination, damaged cells were observed to form cellular aggregations in the outer layer of the epidermis (Miyazaki et al. 1989), which was due to firm junctions between herpesvirus-infected cells in EM. EM and histological evaluation revealed that the primary pathological change was necrosis of epithelial cells infected with the herpesvirus in the epidermal lesions. Thus, herpesvirus-infected cells did not appear to cause hyperplasia. In order to allow the epidermis to recover from damage, an increase in epithelial cells that were normal in appearance compensated for necrotic cells in the deeper region. Definite hyperplasia of the epidermis has been observed in koi Cyprinus carpio koi infected with CyHV-1 (carp pox herpesvirus), and the hyperplastic lesions consisted of cells with distinct features of various organelles as visualized with EM (T. Miyazaki unpubl. data).

Why did herpesvirus-infected cells not separate from the epidermis? In this case, virions entered vesicles in the cytoplasm and were transported to the periphery of the cells to be released through the cell membrane.

Editorial responsibility: Jo-Ann Leong,

Kaneohe, Hawaii, USA
Even in necrotic cells, pieces of fragmented nuclei contained nucleocapsids, and intracytoplasmic vesicles contained virions. The firm junctions of the herpesvirus-infected cells were convenient for more virions to mature and to be released from a cell. Based on the ultrastructural evaluation in this study, the name Viral Epidermal Necrosis (VEdN) is the appropriate name for this flounder herpesvirus infection.

\section{LITERATURE CITED}

Iida Y, Masumura K, Nakai T, Sorimachi M, Masuda H (1989) A viral disease in larvae and juveniles of the Japanese flounder Paralichthys olivaceus. J Aquat Anim Health 1: 7-12

Miyazaki T, Fujiwara K, Kobara J, Matsumoto N, Abe M, Nagano T (1989) Histopathology associated with two viral diseases of larval and juvenile fishes: epidermal necrosis of the Japanese flounder Paralichthys olivaceus and epithelial necrosis of black sea bream Acanthopagrus schlegeli. J Aquat Anim Health 1:85-93

Muroga K (1997) Viral diseases of cultured marine fish in Japan. In: New approaches to viral diseases of aquatic animals. NRIA International Workshop, Kyoto, p 12-21

Submitted: December 6, 2004; Accepted: May 27, 2005

Proofs received from author(s): August 22, 2005 